\title{
Optimization of Biodiesel Injection Parameters Based on Support Vector Machine
}

\author{
Fuxi Shi, ${ }^{1}$ Jun Chen, ${ }^{1}$ Yang Xu, ${ }^{2}$ and Hamid Reza Karimi ${ }^{3}$ \\ ${ }^{1}$ College of Mechanical and Electronic Engineering, Northwest A\&F University, No. 22, Xinong Road, Yangling, Xian, \\ Shaanxi 712100, China \\ ${ }^{2}$ College of Information Engineering, Northwest A\&F University, No. 22, Xinong Road, Yangling, Xian, Shaanxi 712100, China \\ ${ }^{3}$ Department of Engineering, Faculty of Technology and Science, University of Agder, Service Box 509, 4898 Grimstad, Norway
}

Correspondence should be addressed to Jun Chen; cmee.chen@gmail.com

Received 1 March 2013; Accepted 13 March 2013

Academic Editor: Rongni Yang

Copyright (C) 2013 Fuxi Shi et al. This is an open access article distributed under the Creative Commons Attribution License, which permits unrestricted use, distribution, and reproduction in any medium, provided the original work is properly cited.

For the running diesel engine, spray-atomization, mixed-combustion, and thermal-power conversion processes are inseparable, which causes difficulty to investigate atomization effect separately. This study was conducted to improve the atomization efficiency of the soybean fatty acid methyl ester (SFAME) in engine, to achieve the minimum effective specific fuel consumption in specific engine working conditions, the different injection parameters combination were explored on the influence of effective specific fuel consumption at elevated fule temperature. The effective specific fuel consumption prediction model was established based on support vector machine (SVM). With small samples, the intrinsic functional relationship was determined and the best injection parameters were validated under seven different experimental conditions. The study results have shown that the engine's spray-thermal-power conversion process could be simulated accurately by using SVM. It will be more favorable to improve application effect of biodiesel in the engine to select the fuel temperature as injection parameters which influence atomization effect. Furthermore, using enumeration-verification methods to simulate the parameters might save a lot of resources as compared to the similar experiments.

\section{Introduction}

With the increasing shortage of oil resources and continual strictness of environmental restrictions, biodiesel, which has advantages of less exhaust pollution, widely raw material [1], and completely biodegradation, and so forth [2], has become the most ideal substitute for fossil diesel fuel.

Diesel engine is designed to run diesel; so, biodiesel cannot match atomization system structure and parameters, and there are some drawbacks to use biodiesel directly in existing diesel engine, such as poor atomization, advanced ignition timing, and declining combustion efficiency because of larger viscosity, lower calorific value, and higher oxygen content of biodiesel [3]. As a result, the parameters of engine including the torque, rotational speed, and emission should be changed. Therefore, it is a significant issue to use biodiesel on engine to improve the atomization efficiency of biodiesel. To improve the atomization efficiency of biodiesel by elevating the fuel temperature is an effective solution of application and promotion, but distribution of fuel temperature and spray parameters needs to be optimized. Actual engine experiment to study atomization effect will face to more technology difficulty, higher experimental cost, and complicated verification process.

For a diesel engine, spray-atomization, mixed-combustion, and thermal-power conversion were inseparable; the whole process can be expressed as a complex function and be simulated through mathematical algorithm, finally to explore the optimal parameters combination of biodiesel atomizing. It is a key factor to choose a suitable algorithm for the application issue. Thangaraj et al. [4] introduced a new vector on the basis of particle swarm optimization algorithm, called the BPSO algorithm, to achieve the biodiesel atomizing. Jabeen and Baig [5] proposed a particle swarm optimization algorithm in antenna applications and improved the particle swarm optimization algorithm. Vegh et al. [6] improved 
differential evolution and the precision to find the optimal solution in search space. However, the algorithms mentioned earlier can be very good in space to find the optimal solution, but all the samples have a higher demand at the quality and quantity of data.

Although the engine spray system involves many parameters, the amount of data obtained by engine experiment is limited. Hence, the number of experimental samples is small relatively to their dimensionality, and the SVM theory is good at solving small sample learning problems [7]. The proposed method has good generalization, high-dimensional processing, and powerful nonlinear processing capabilities and is used more and more widely in the field of agricultural engineering.

In this paper, the adaptability between SFAME and fuel supply system of the engine was analyzed from the macro perspective on optimization of the injection parameters. According to the changes of input and output parameters and based on SVM, the intrinsic functional relationship between effective specific fuel consumption (ESFC) and injection parameters combination were determined by using small sample in specific experimental conditions. Then accordingly, the best injection combined parameters of biodiesel were predicted by the intrinsic functional and were verified by the corresponding experiment, and we propose the basic idea of injection parameters optimizing to better use biodiesel in existing engines.

\section{Basic Theory}

After Fuels jet from the fuel injector under the given injection combined parameters, the actual produced heat energy were decided by the atomization efficiency and combustion efficiency in cylinder together, and then through the thermalpower conversion mechanism, effective power can be gained from power-output shaft of engine by the torque and speed. At working stably in specific conditions, there is a certain relationship between effective thermal efficiency and indicated thermal efficiency [8], as shown in formula (1). Here, mechanical efficiency of engine $\eta_{m}$ and low calorific value of fuel $H_{u}$ are fixed value; so, indicated thermal efficiency and ESFC show an inversely proportional relationship. Consider

$$
\eta_{\mathrm{it}}=\frac{\eta_{\mathrm{et}}}{\eta_{m}}=\frac{3.6 \times 10^{6}}{g_{e} \cdot H_{u} \cdot \eta_{m}}=\frac{C_{0}}{g_{e}},
$$

wherein symbols in the formula have the following meanings:

$\eta_{\mathrm{et}}:$ effective thermal efficiency,

$\eta_{\mathrm{it}}:$ indicated thermal efficiency,

$\eta_{m}:$ mechanical efficiency,

$H_{u}$ : low calorific value of fuel $(\mathrm{KJ} / \mathrm{Kg})$,

$g_{e}:$ effective specific fuel consumption $(\mathrm{g} / \mathrm{KW} \cdot \mathrm{h})$,

$C_{0}=3.6 \times 10^{6} / H_{u} \cdot \eta_{m}$.
Based on the experimental parameters, the indicated thermal efficiency can be converted into

$$
\eta_{\text {it }}=\frac{3.6 \times 10^{3} P_{e}}{G_{T} \cdot H_{u} \cdot \eta_{m}}=\frac{\pi \cdot M_{e} \cdot n \cdot s}{30 \cdot \Delta g \cdot H_{u} \cdot \eta_{m}}=\frac{C_{1} \cdot M_{e} \cdot n}{\Delta g / s},
$$

wherein symbols in the formula have the following meanings:

$$
\begin{aligned}
& M_{e}: \text { torque }(\mathrm{N} \cdot \mathrm{m}), \\
& n \text { : rotate speed }(\mathrm{r} / \mathrm{min}), \\
& s: \text { recording time of fuel consumption instrument }(\mathrm{s}) \text {, } \\
& G_{T}: \text { hour fuel consumption }(\mathrm{Kg} / \mathrm{h}), \\
& \Delta g: \text { measurement quality of fuel consumption instru- } \\
& \text { ment }(\mathrm{g}), \\
& C_{1}=\pi / 30 H_{u} \cdot \eta_{m} .
\end{aligned}
$$

In formula (2), measurement quality of fuel consumption instrument $\Delta g$ is $20 \mathrm{~g}$, the mechanical efficiency of diesel engine usually changes between 0.7 and 0.85 , and its value is stable when engine runs stably in a specific condition. $\Delta g / s$, as input factors can express cycle fuel delivery indirectly. As output factors, $M_{e} n$ and indicated thermal efficiency show positively proportional relationship. In the constant engine load, torque and speed are stable; if atomization effect has been improved at elevating biodiesel temperature, cycle fuel delivery would be reduced, which improves indicated thermal efficiency.

By data mining the possible intrinsic function relations between indicated thermal efficiency and engine parameters, some injection parameters were introduced into function of indicated thermal efficiency, which is conducive to analyze injection parameters on the atomization, combustion, and thermal-power conversion process of comprehensive effect. Formula (3) is a model function of thermal-power conversion created based on experimental measured parameters, after the injection parameters were added. Consider

$$
\eta_{\mathrm{it}}=F\left(M_{e}, n, t, \Delta g, T_{i}, P_{i}, T_{o}, T_{w}, T_{p}, T_{h}, P_{s}, \varepsilon, \varphi\right) .
$$
follows:

The meaning of the symbols in the formula is shown as

$T_{i}$ : air inlet temperature,

$P_{i}$ : admission pressure,

$T_{o}$ : exhaust temperature,

$T_{w}$ : water temperature,

$T_{p}$ : injected temperature,

$P_{s}$ : injection pressure,

$T_{h}$ : high-pressure fuel line temperature,

$T_{p}$ : pressure chamber temperature,

$\varepsilon$ : compression ratio,

$\varphi$ : advance angle of injection,

$t$ : injection duration. 
Formula (3) comprehensively reflects indicated thermal efficiency of the component factors and thermal-power conversion process from injection to the piston power; if function $F$ can be simulated, the conversion relationship between parameters of injection control system and indicated thermal efficiency can be expressed, further to achieve optimization of injection configuration parameters.

\section{Analysis of Injection Parameters of Biodiesel}

Atomization effect usually uses spray cone angle, spray penetration, and atomization droplet size to evaluate, but the "atomization efficiency" concept expressed the adaptation level of spray effect on combustion inside cylinder [9]. If engine is in specific conditions, fuel spray effect can match combustion environment inside cylinder, and it never causes negative effect for combustion process; here, the atomization efficiency is $100 \%$. As shown in formula (4), indicated thermal efficiency is regarded as a combination including injection efficiency, combustion efficiency, and thermal conversion efficiency [10]. Consider

$$
\eta_{\mathrm{it}}=\eta_{s} \cdot \eta_{c} \cdot \eta_{t}=\frac{C_{0}}{g_{e}} .
$$

The meaning of the symbols in the formula is shown as follows:

$$
\begin{aligned}
& \eta_{s}: \text { spray efficiency, } \\
& \eta_{c}: \text { combustion efficiency, } \\
& \eta_{t}: \text { thermal-power conversion efficiency. }
\end{aligned}
$$

To elevate fuel temperature, the bulk modulus, velocity of sound, kinematic viscosity, surface tension, and saturated steam pressure of biodiesel can be decreased [11, 12], which can change the pressure transmitting of fuel and flow condition in the pipe line, Cavitation number and Reynolds number in orifice, and Weber number and Ohnesorge number of liquid jet, thus biodiesel fuel injection and atomization process were comprehensive affected with elevated temperature fule [13]. To reflect the fuel temperature effect on atomization, high pressure this fuel line temperature and pressure chamber fule temperature are new parameters proposed by this paper, the reason is that the pressure chamber is more close to the injector orifice and the pressure chamber fule temperature can also more approximately stand for injection temperature of fule actual spurt.

In this study, injection pressure, injection duration, and high pressure fuel line temperature, pressure chamber temperature were chosen as part of injection system control parameters, through adjusting and matching them in the experimental process, to keep the torque and speed of engine stability in same working condition, which fully highlighted the fuel temperature on atomization effect. Because spray effect is determined by several factors, the parameters of spray system also include injection pulse number and distribution, Nozzle geometry parameters, high-pressure fuel pump performance parameters, and fuel supply line structure, which are also important to the spray system [14]. However, for a running engine in the specific condition, these parameters are certain and can be ignored on the ability to change atomization effect. Hence, these injection parameters are set as constants in this paper.

In order to emphatically present the influence of the spray effect under changing fuel temperature, formula (5) shows that the effect of chosen injection parameters on spray efficiency. Consider

$$
\eta_{s}=\frac{\eta_{\text {it }}}{\eta_{c} \cdot \eta_{t}}=\frac{C_{2}}{g_{e}}=G\left(P_{s}, t, T_{h}, T_{p}, C_{s}\right) .
$$

Here, $C_{s}$ is a selective constant by working condition, and $C_{2}=3.6 \times 10^{6} / H_{u} \cdot \eta_{m} \cdot \eta_{c} \cdot \eta_{t}$.

Here, indicated thermal efficiency is used as the link parameter between controlled parameters and engine outputs. Under the same operating condition, the parameters $\eta_{c}$, $\eta_{t}$ working are the fixed values, and $C_{2}$ is a constant, while atomization efficiency and effective specific fuel consumption are in inverse ratio relation. Because $\eta_{s}$ cannot be calculated, $g_{e}$ can be acquired by using experimental data, as shown in formula (6). In this case, atomization efficiency is decided by the four selected parameters which are atomization efficiency, and the lower effective specific fuel consumption. Hence, formula (5) can be represented as formula (7). Consider

$$
\begin{aligned}
& g_{e}=\frac{3.6 \times 10^{6} \Delta g}{\pi \cdot M_{e} \cdot n \cdot s}, \\
& g_{e}=\frac{C_{2}}{\eta_{s}}=H\left(P_{s}, t, T_{h}, T_{p}, C_{\mathrm{it}}\right) .
\end{aligned}
$$

Here, $C_{i t}$ is a selective constant by working condition.

According to formula (7), many groups of experiments data were acquired, SVM model constructing and function fitting were carried out based on these data, and then one achieved prediction of ESFC for seven different experimental conditions. Finally, optimum combination parameters of injection system can be confirmed.

\section{Optimization of Spray Model Using SVM}

SVM based on the statistical learning theory is a generic learning method. SVM can map data points (input parameters) into a higher dimensional input space using nonlinear transformation and construct a hyper plane, which can be used for sample classification or prediction [14].

4.1. Construction of the SVM Model. SVM can be well applied to functional fitting problems, to find the essential relationship among the data and express its inherent and complicated function relationship. Once algorithm model is constructed, relevant parameters can be divided into two parts. In the paper, the impact factors were considered including injection pressure, injection duration, high-pressure fuel pipe temperature, pressure chamber temperature, and the effective specific fuel consumption.

Supposing that there is fuel injection examples $\left(x_{i}, y_{i}\right)$ $(i=1,2, \ldots, k), x \in R^{n}$ denotes the factor of influencing 


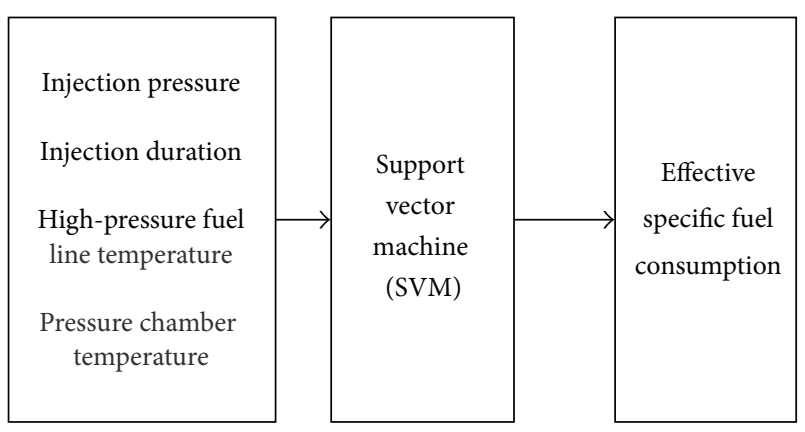

FIGURE 1: SVM parameter model.

injection efficiency and $y_{i}$ denotes the index of effective specific fuel consumption. And here, $y_{i} \in R$ means thermalpower conversion efficiency. In a word, construction of the SVM spray model tries to find the relationship between $x_{i}$, $y_{i}$ :

$$
\begin{gathered}
H: R^{n} \longrightarrow R, \\
y_{i}=H\left(x_{i}\right) \quad(i=1,2,3, \ldots, k) .
\end{gathered}
$$

In formula (9), $R^{n}$ represents the four parameters which affect injection efficiency which are injection pressure, injection duration, high-pressure fuel pipe temperature, and pressure chamber temperature. $R$ is the index of thermal-power conversion efficiency, in other words, indicated thermal efficiency. The initial model of SVM is shown in Figure 1.

After determining input and output of the model, firstly, data obtained from engine experiments are preprocessed, including standardization and abnormal point elimination, and preliminarily choose kernel function and set relaxing factors $C$ and $\lambda$. Secondly, through learning and verifying these data, types of the function and factors are confirmed. And finally the prediction model can be determined. The flow chart of SVM model construction is shown in Figure 2.

For a certain condition (such as rated load), using prediction model, according to the range of four parameters, we study the maximum of ESFC and obtain the best combination of parameter in the end. The optimization process of other load states is basically the same as this one. Figure 3 shows the process of parameters optimizing and testing.

4.2. Target and Parameter Settings of SVM. After establishing the SVM model, data predicting and parameters optimizing can be implemented according to research targets.

4.2.1. Research Targets. According to formula (7), Table 1 shows our research targets. Using model injection parameters $P_{s}, t, T_{h}, T_{p}$ and the SVM model $H()$, we implement the prediction of effective specific fuel consumption $g_{e}$.

4.2.2. Parameter Settings. After the research target and sample set have been determined, the corresponding parameters of SVM should be chosen, including kernel function, penalty factor, and gamma value. After a preliminary exploration,

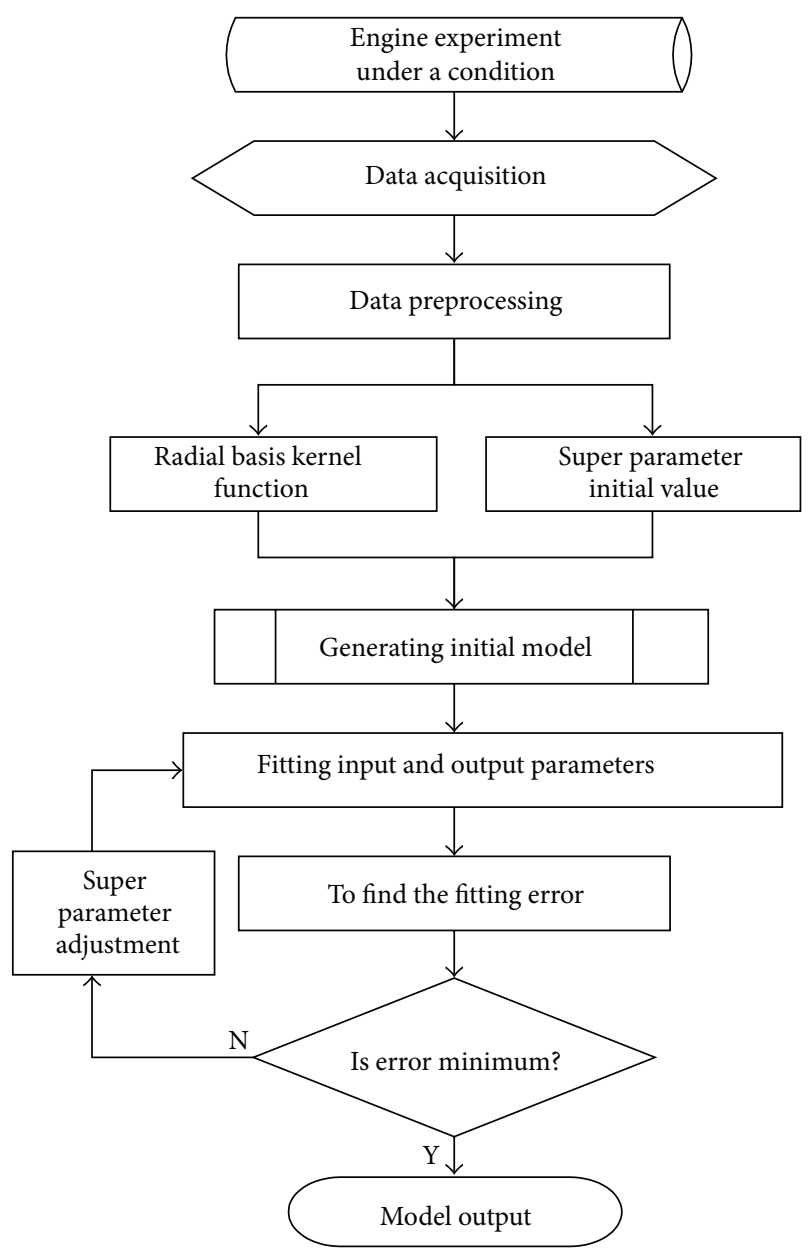

Figure 2: Flow chart of SVM model construction.

TABLE 1: Research target of SVM.

\begin{tabular}{lcc}
\hline Function & Model parameter & Prediction \\
\hline$H()$ & $P_{s}, t, T_{h}, T_{p}$ & $g_{e}$ \\
\hline
\end{tabular}

the RBF kernel function was as kernel function, as shown in formula (10). Consider

$$
K(x, y)=\exp \left(-\frac{|x-y|^{2}}{\sigma^{2}}\right) .
$$

The great difference between our classifier and traditional method RBF is that the center of each basis function corresponds to a support vector, which is confirmed automatically by algorithm together with output weights [15].

Among them, the value of penalty factor is 2 and the value of gamma is 0.25 . In the experiment, we use libsvm software package and run it in the software weka. The initial parameters are listed in Table 2.

4.3. Experimental Methods. In our experiment, a singlecylinder natural aspirated swirl chamber S195 diesel engine was used. Its cylinder diameter, stroke, rated power, rated 
TABLE 2: SVM's initial parameter.

\begin{tabular}{lc}
\hline Parameter & Value \\
\hline Type of SVM & nu-SVR \\
Type of kernel function & Radial basis function \\
gamma in the kernel function & 0.25 \\
Degree in the kernel function & 3 \\
Parameter $n$ & 0.5 \\
Buffer size & 100.0 \\
Penalty coefficient $C$ & 2 \\
Terminated tolerated deviation & 0.001 \\
$e$ in the loss function & 0.1 \\
\hline
\end{tabular}

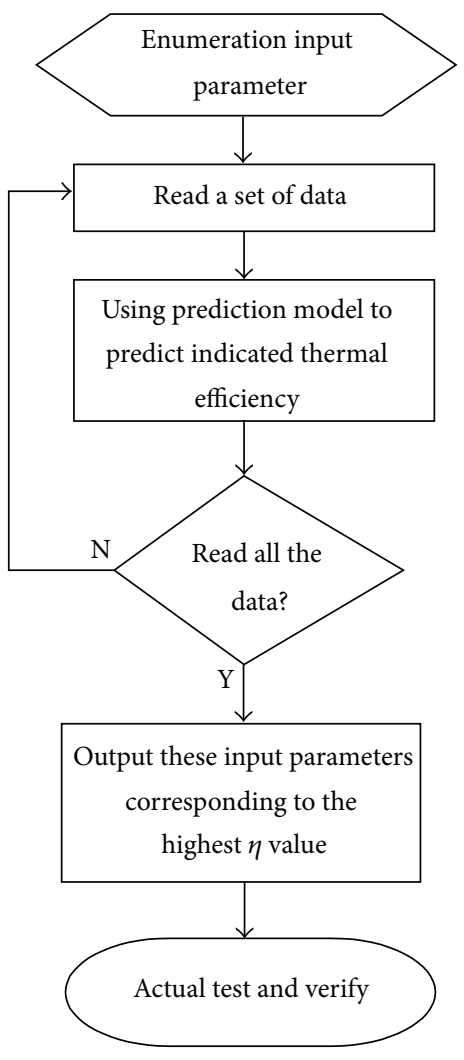

FIGURE 3: Flow chart of parameter optimizing.

speed, and compression are $95 \mathrm{~mm}, 115 \mathrm{~mm}, 10.6 \mathrm{Kw}$, $2200 \mathrm{r} / \mathrm{min}$, and 20, respectively. SFAME is used as test oil, and admission pressure is $0.98 \mathrm{MPa}$, air inlet temperature is $20^{\circ} \mathrm{C}$, and air relative humidity is $60 \% \mathrm{HC}$. Seven different conditions are chosen in this paper, power values of which, respectively, are $0.47 \mathrm{kw}, 1.55 \mathrm{kw}, 3.11 \mathrm{kw}, 4.67 \mathrm{kw}$, $6.23 \mathrm{kw}, 7.79 \mathrm{kw}$, and $9.35 \mathrm{kw}$. Forty experiments were carried out under each condition and then picked up 35 times experimental data as training samples. The remaining 5 experimental data are regarded as test samples.

4.4. Experimentation on SVM. After preprocessing the data, we begin to train the training samples in SVM.
TABLE 3: SVM training results.

\begin{tabular}{lc}
\hline Content & Value \\
\hline Iterations & 8357 \\
$\varepsilon$ & 0.001649 \\
Quadratic programming to solve the small value & -0.257941 \\
Constant of decision function & -0.101155 \\
The total number of support vectors & 27 \\
The number of support vector of boundary & 10 \\
\hline
\end{tabular}

TABLE 4: The model obtained from SVM training.

\begin{tabular}{lc}
\hline Content & Value \\
\hline Type of SVM & nu-SVR \\
Type of kernel function & Radial basis function \\
Gamma in the kernel function & 0.25 \\
Category number & 2 \\
The total number of support vector & 34 \\
Constant of decision function & -0.101155 \\
\hline
\end{tabular}

TABLE 5: Effective specific fuel consumption forecast results.

\begin{tabular}{lccc}
\hline Sample & Real value g/KW·h & Predicted value g/KW·h & Error/\% \\
\hline 1 & 184.110187 & 184.224151 & 0.0619 \\
2 & 183.299389 & 183.321201 & 0.0119 \\
3 & 182.741116 & 182.579207 & -0.0886 \\
4 & 183.473684 & 183.440475 & -0.0181 \\
5 & 181.104477 & 181.132367 & 0.0154 \\
\hline
\end{tabular}

TABLE 6: Effective specific fuel consumption forecast results evaluation.

\begin{tabular}{lc}
\hline Content & Value \\
\hline Error of mean square & $2.51568 e-5$ \\
Correlation of square coefficient & 0.826093 \\
\hline
\end{tabular}

TABLE 7: Injection parameter selection.

\begin{tabular}{lcc}
\hline Content & Value range & Step value \\
\hline Injection pressure & $12 \sim 19 \mathrm{MPa}$ & $0.1 \mathrm{MPa}$ \\
Injection duration & $14.2 \sim 5.6^{\circ} \mathrm{CaA}$ & $0.1^{\circ} \mathrm{CaA}$ \\
High-pressure oil pipe temperature & $67 \sim 89^{\circ} \mathrm{C}$ & $1^{\circ} \mathrm{C}$ \\
Pressure chamber temperature & $230 \sim 336^{\circ} \mathrm{C}$ & $1^{\circ} \mathrm{C}$ \\
\hline
\end{tabular}

4.4.1. SVM Training. Training process is the optimization of training set and fitting of decision-making parameters process. After training 35 training samples of $1.55 \mathrm{KW}$ indicated power in SVM, the result is listed in Table 3.

After 8357 iterations, optimal results are obtained by SVM and SVM training model as listed in Table 4.

In addition, the result document of training model also records all values of support vectors. Theoretically, the more number of SVM, the more restrictions at the forecast period, 
TABLE 8: Best injection parameters.

\begin{tabular}{|c|c|c|c|c|c|}
\hline Output power/Kw & $\begin{array}{c}\text { Injection } \\
\text { pressure/MPa }\end{array}$ & $\begin{array}{c}\text { Injection } \\
\text { duration } /{ }^{\circ} \mathrm{CaA}\end{array}$ & $\begin{array}{c}\text { High-pressure oil } \\
\text { pipe temperature } /{ }^{\circ} \mathrm{C}\end{array}$ & $\begin{array}{l}\text { Pressure chamber } \\
\text { temperature } /{ }^{\circ} \mathrm{C}\end{array}$ & $\begin{array}{l}\text { Minimum effective } \\
\text { specific fuel } \\
\text { consumption } / \mathrm{g} / \mathrm{Kw} \cdot \mathrm{h}\end{array}$ \\
\hline 0.47 & 15.7 & 6.3 & 67 & 233 & 582.128650 \\
\hline 1.55 & 13.8 & 9.1 & 71 & 248 & 181.086519 \\
\hline 3.11 & 15 & 7.4 & 74 & 259 & 124.481927 \\
\hline 4.67 & 13.2 & 9.4 & 76 & 269 & 102.739726 \\
\hline 6.23 & 14.85 & 11.85 & 80 & 278 & 98.814229 \\
\hline 7.79 & 15.77 & 12.75 & 84 & 287 & 89.775561 \\
\hline 9.35 & 18.56 & 12.38 & 90 & 301 & 94.043887 \\
\hline
\end{tabular}

TABLE 9: The best injection parameters effect validation.

\begin{tabular}{lccccc}
\hline Sequence number & Injection pressure/MPa & Duration $/{ }^{\circ} \mathrm{CaA}$ & $\begin{array}{c}\text { High-pressure oil } \\
\text { pipe temperature } /{ }^{\circ} \mathrm{C}\end{array}$ & $\begin{array}{c}\text { Pressure chamber } \\
\text { temperature } /{ }^{\circ} \mathrm{C}\end{array}$ & $\begin{array}{c}\mathrm{ESFC} / \mathrm{g} / \mathrm{Kw} \cdot \mathrm{h} \\
1\end{array}$ \\
\hline 13.8 & 9.1 & 71 & 248 & 181.086519 \\
2 & 13.7 & 9.1 & 71 & 248 & 185.567010 \\
3 & 13.8 & 9 & 71 & 248 & 183.673469 \\
4 & 13.8 & 9.1 & 70 & 248 & 184.994861 \\
5 & 13.8 & 9.1 & 71 & 247 & 182.186234 \\
\hline
\end{tabular}

and the prediction results are more accurate. We can test the test sample based on the model [16].

4.4.2. Samples Testing. Using the model obtained from Section 4.4.1, we can predict 5 test samples. The result is listed in Table 5. The results have shown that the prediction error is within the range of $\pm 0.09 \%$.

4.4.3. Results Evaluation. Although there is not too much of forecast difference, from the point of mathematics, the accuracy of the prediction results needs to be confirmed and evaluated. The evaluation of prediction results of ESFC are showen in Table 6.

The results have shown that the correlation of input and output parameters is higher and the error of mean square is under $10^{-5}$, which indicates that the result is accurate and reliable.

4.5. Selection of Optimum Injection Parameters. According to parameters of diesel engine and experience accumulation, spans and steps of parameters are set in Table 7.

Due to small number of parameters and small range of values, enumeration method can be used to get all combinations of injection parameters $[17,18]$. According to the range of value and step value, 14,987,490 sets of alternative data are obtained by enumerating. Powers of them, respectively, are $0.47 \mathrm{kw}, 1.55 \mathrm{kw}, 3.11 \mathrm{kw}, 4.67 \mathrm{kw}, 6.23 \mathrm{kw}, 7.79 \mathrm{kw}$, and $9.35 \mathrm{kw}$ conditions. Using what is described in Section 4.4.1 to get the training results and evaluate all the samples of alternative data, we can get the best injection parameters as listed in Table 8.
In the test results, the sample, whose value of ESFC is maximum, may be considered as its best injection parameters. And we also need to do a practical test to get objective conclusions.

\section{Verification of SVM Prediction}

For the best injection parameters in Section 4.5, actual verification is done under different engine load. The verified methods are as follows. Firstly, deviating separately from four dimensions, we observe change situations of injection efficiency. Secondly, by comparison, we verify the best injection combination.

Taking power $1.55 \mathrm{kw}$ as an example, the verification data of engine experimentation is shown in Table 9.

Through the verification experiment, three results can be confirmed. Firstly, when getting the best injection parameters, the actual ESFC is different from the predicted value, but very close to it. It shows that the predicted result is accurate. Secondly, support vector deviating from any dimension, the result can reduce indicated thermal efficiency. So it can be verified that training results in Section 4.5 are the best parameters of injection combination. Thirdly, after the six kinds of working conditions are tested, the conclusion is the same with (1) and (2).

Figure 4 shows the difference of engine test results with the optimized parameters combination and the original parameters combination under different working conditions, which indicates that effective fuel consumption rate is improved obviously when the engine uses optimized parameters combination, and with the increase of power the improvement effect is more obvious. It can be seen that the 


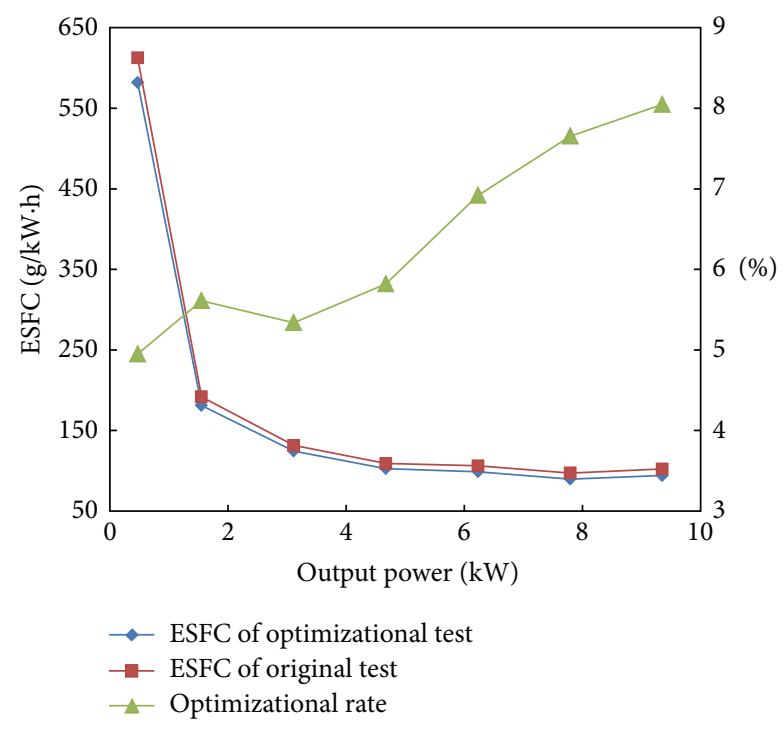

FIGURE 4: ESFC improvement in engine test after optimization.

ESFC decreases $5 \% \sim 8 \%$, which illustrates the effectiveness of the SVM method for optimization and gets the optimal spray parameter combination.

\section{Conclusion}

Using SVM method under the condition of small sample is able to realize the function simulation between fuel Pinjection key parameters and effective specific fuel consumption corresponding relationship from the macroscopic angle to highlight the influence of injection conditions on the engine thermal-power conversion process. This work can provide reference for the improvement of fuel supply system.

(1) SVM can make more accurate fitting to the model of thermal-power conversion of engine by predicting effective specific fuel consumption and determining the best injection parameters.

(2) To select the fuel temperatures which influence atomization effect as injection parameters will be more favorable to improve application effect of biodiesel in the engine.

(3) Using exhaustive testing method to analog parameters can save a large amount of resources under the same experimental conditions.

(4) Assessment results, as evaluating basis of injection parameters of biodiesel, provide a new idea to obtain the optimized combination parameters of fuel supply system and atomization device.

\section{References}

[1] A. Demirbas, "Progress and recent trends in biodiesel fuels," Energy Conversion and Management, vol. 50, no. 1, pp. 14-34, 2009.
[2] E. Z. Min, Z. Tang, Z. X. Du, and W. Wu, "Perspective of biodiesel industry in China," Chinese Engineering Science, vol. 7, no. 4, pp. 1-4, 2005.

[3] Y. N. Yuan, T. Zhang, D. Q. Mei, and P. Sun, "Investigation on combustion characteristics of direct injection diesel engine fuelled with biodiesel," Transactions of CSICE, vol. 25, no. 1, pp. 43-46, 2007.

[4] R. Thangaraj, M. Pant, A. Abraham, and V. Snasel, "Modified particle swarm optimization with time varying velocity vector," International Journal of Innovative Computing, Information and Control, vol. 8, no. 1, pp. 201-218, 2012.

[5] H. Jabeen and A. R. Baig, "GPSO: a framework for optimization of genetic programming classifier expressions for binary classification using particle swarm optimization," International Journal of Innovative Computing, Information and Control, vol. 8, no. 1, pp. 233-242, 2012.

[6] V. Vegh, G. K. Pierens, and Q. M. Tieng, "A variant of differential evolution for discrete optimization problems requiring mutually distinct variables," International Journal of Innovative Computing, Information and Control, vol. 7, no. 2, pp. 897-914, 2011.

[7] T. Van Gestel, J. A. K. Suykens, B. Baesens et al., "Benchmarking least squares support vector machine classifiers," Machine Learning, vol. 54, no. 1, pp. 5-32, 2004.

[8] B. D. Gong, S. Z. Cun, and D. C. Zhou, "The main factors of calculation method and influence error about the heat release rate and conbustion ratio of diesel engine," Vehicle Engine, 1980.

[9] M. F. Yao, Z. Q. Zheng, Y. Luo, and S. D. Xu, "Experimental study of the influence of injection parameters on the spray and combustion process of dimethyl ether," Journal of Combustion Science and Technology, vol. 9, no. 4, pp. 339-343, 2003.

[10] Z. Xin, Y. Zhang, S. X. Wang, Y. L. Zhang, and J. X. Liu, "Influence factors of DeNO_x behavior in urea-SCR catalytic converter of diesel," Journal of Agricultural Machinery, vol. 42, no. 9, pp. 30-34, 2011.

[11] C. E. Ejim, B. A. Fleck, and A. Amirfazli, "Analytical study for atomization of biodiesels and their blends in a typical injector: surface tension and viscosity effects," Fuel, vol. 86, no. 10-11, pp. 1534-1544, 2007.

[12] M. Dzida and P. Prusakiewicz, "The effect of temperature and pressure on the physicochemical properties of petroleum diesel oil and biodiesel fuel," Fuel, vol. 87, no. 10-11, pp. 1941-1948, 2008.

[13] P. G. Aleiferis, J. Serras-Pereira, A. Augoye, T. J. Davies, R. F. Cracknell, and D. Richardson, "Effect of fuel temperature on innozzle cavitation and spray formation of liquid hydrocarbons and alcohols from a real-size optical injector for direct-injection spark-ignition engines," International Journal of Heat and Mass Transfer, vol. 53, no. 21-22, pp. 4588-4606, 2010.

[14] Y. Y. Qian, Y. Q. Li, X. M. Yu, and K. Suzuki, "Experiment study on fuel spray on small direct injection diesel engine," Transactions of CSICE, vol. 19, no. 2, p. 97, 2001.

[15] X. G. Zhang, "Introduction to statistical learning theory and support vector machines," Acta Automatica Sinica, vol. 26, no. 1, pp. 32-42, 2000.

[16] Q. A. Tran, Q. Zhang, and X. Li, "Hybrid optimization of feature selection and SVM training model," Journal of Tsinghua University, vol. 44, no. 1, pp. 9-12, 2004.

[17] Y. Y. Chen, Y. Liang, and X. M. Liu, "Orthogonal enumeration method for the layout scheme optimization of road network," China Civil Engineering Journal, vol. 36, no. 7, pp. 14-17, 2003. 
[18] Y. J. Gao, M. Zhou, G. Y. Li, R. Li, and L. M. Xiao, "Available transfer capability calculation based on Markov chain and enumeration method," Proceedings of the Chinese Society of Electrical Engineering, vol. 26, no. 19, pp. 41-46, 2006. 


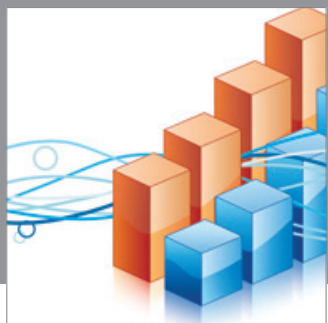

Advances in

Operations Research

mansans

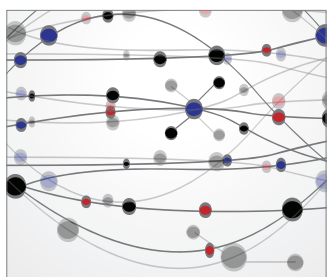

The Scientific World Journal
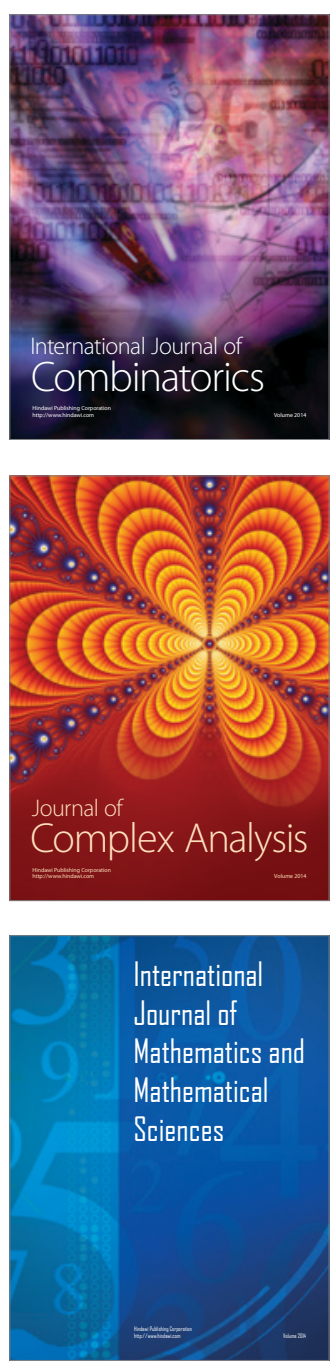
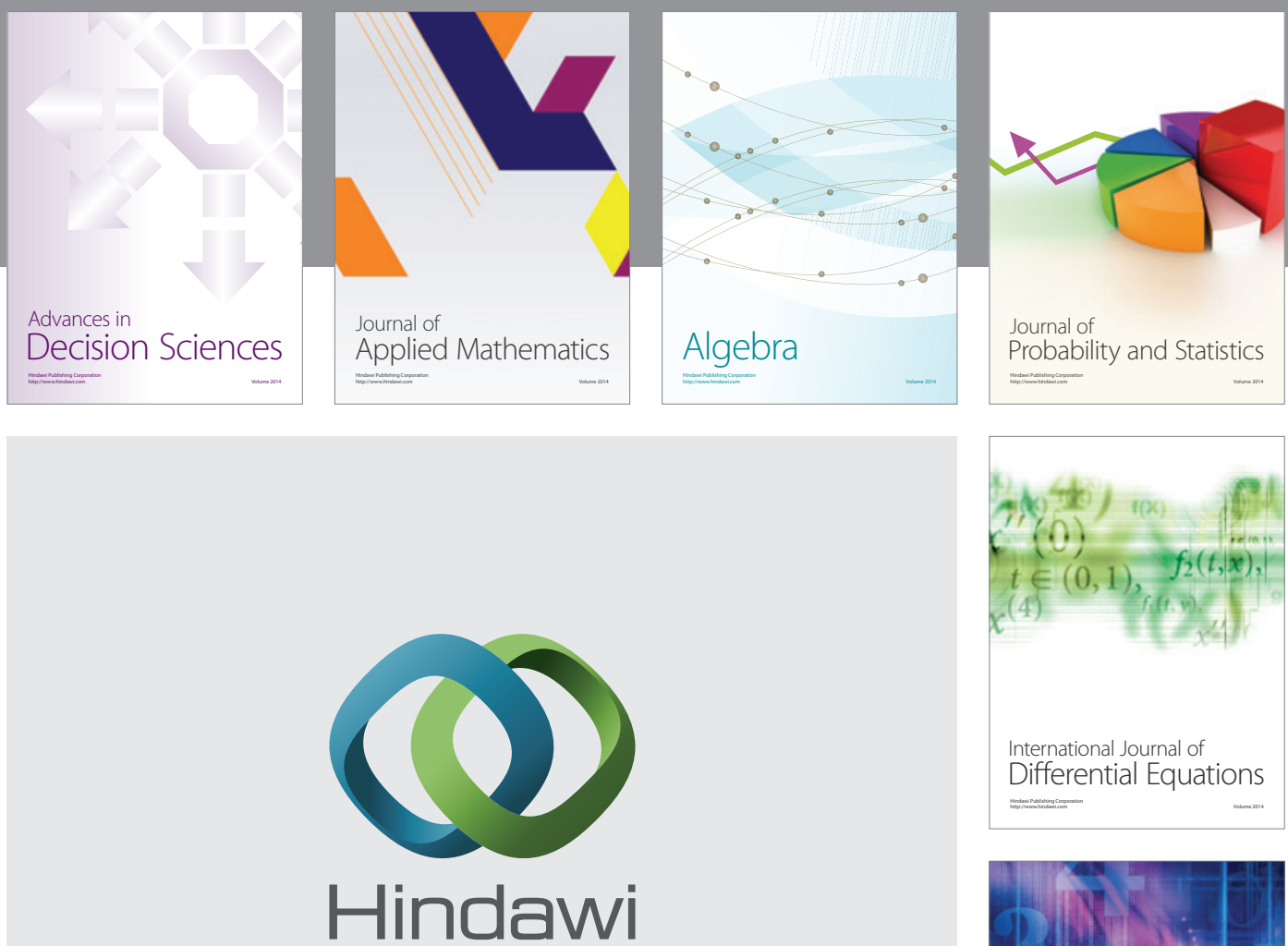

Submit your manuscripts at http://www.hindawi.com
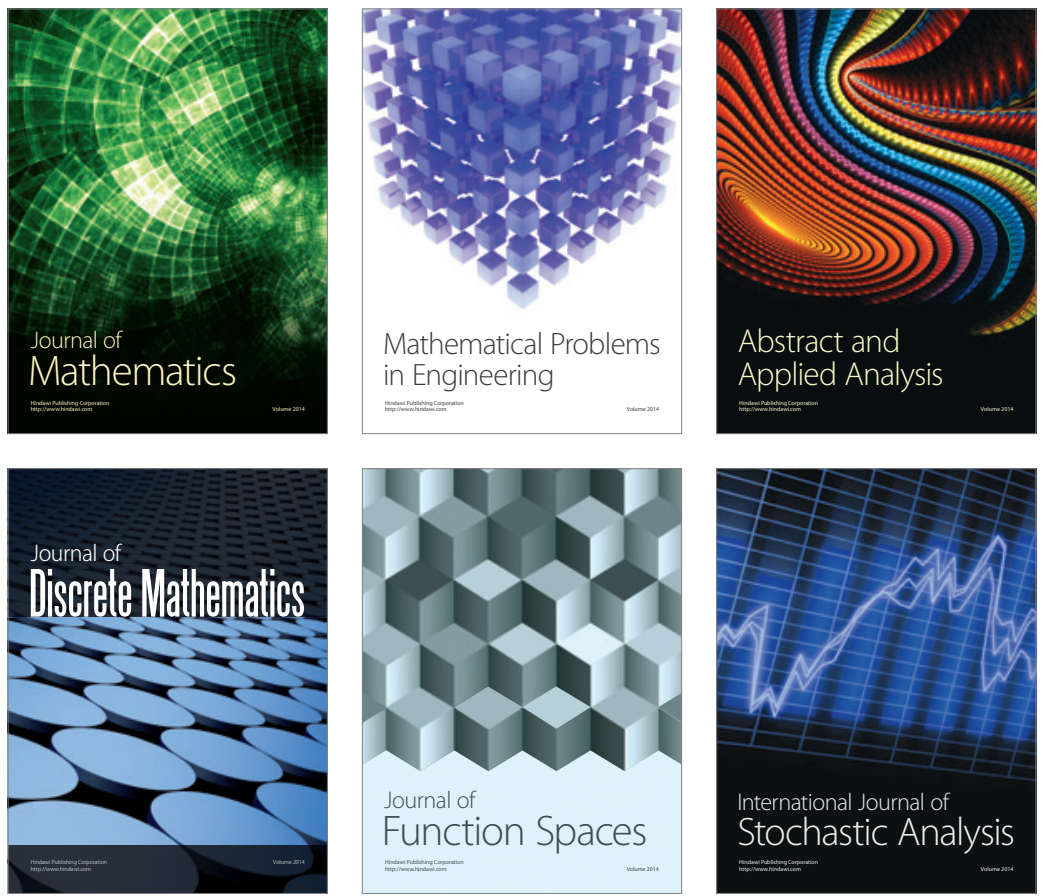

Journal of

Function Spaces

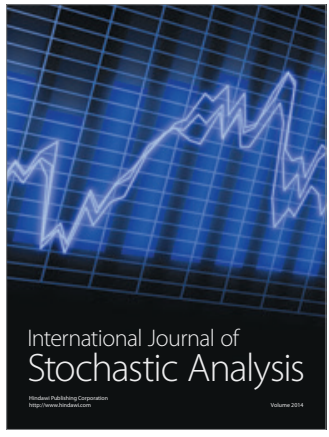

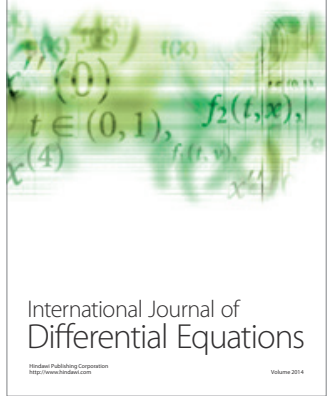
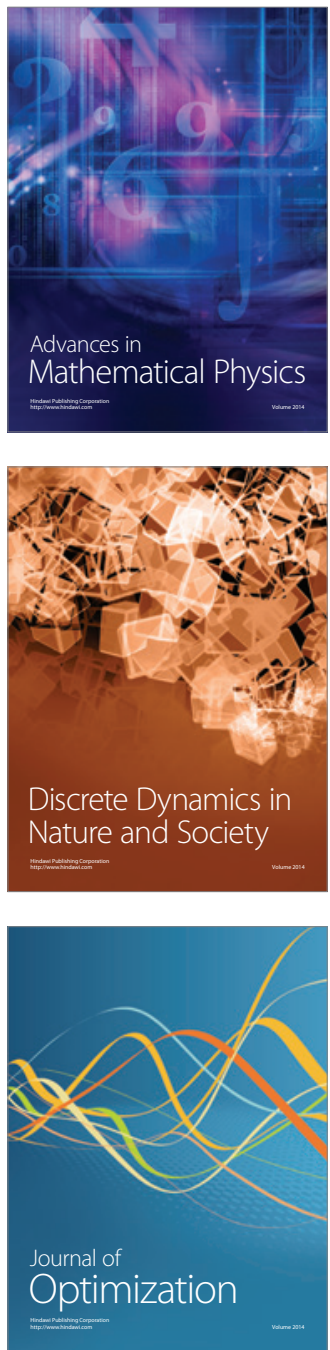